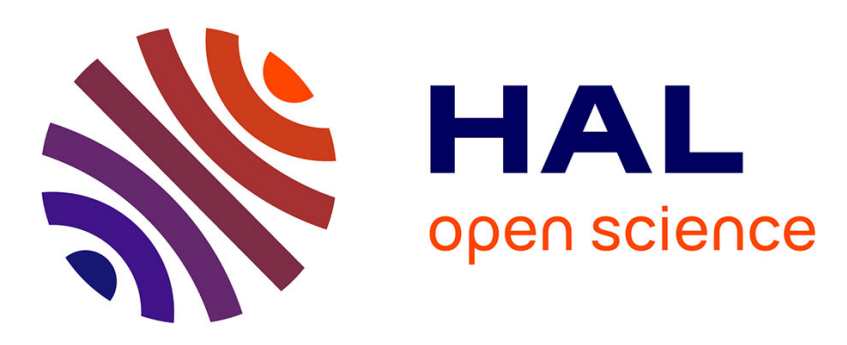

\title{
Active Versus Passive Recovery in High-Intensity Intermittent Exercises in Children: An Exploratory Study.
}

Georges Baquet, Gregory Dupont, François-Xavier Gamelin, Julien

Aucouturier, Serge Berthoin

\section{To cite this version:}

Georges Baquet, Gregory Dupont, François-Xavier Gamelin, Julien Aucouturier, Serge Berthoin. Active Versus Passive Recovery in High-Intensity Intermittent Exercises in Children: An Exploratory Study.. Pediatric Exercise Science, 2019, Pediatric Exercise Science, 31 (2), pp.248-253. 10.1123/pes.2018-0218 . hal-03412452

HAL Id: hal-03412452

https://hal.univ-lille.fr/hal-03412452

Submitted on 3 Nov 2021

HAL is a multi-disciplinary open access archive for the deposit and dissemination of scientific research documents, whether they are published or not. The documents may come from teaching and research institutions in France or abroad, or from public or private research centers.
L'archive ouverte pluridisciplinaire HAL, est destinée au dépôt et à la diffusion de documents scientifiques de niveau recherche, publiés ou non, émanant des établissements d'enseignement et de recherche français ou étrangers, des laboratoires publics ou privés. 
Baquet G, Dupont G, Gamelin FX, Aucouturier J, Berthoin S.

Active Versus Passive Recovery in High-Intensity Intermittent Exercises in Children: An Exploratory Study.

Pediatr Exerc Sci. 2019 May 1;31(2):248-253.

doi: 10.1123/pes.2018-0218. Epub 2019 Mar 24.

PMID: 30907283

Title: Active versus Passive Recovery in High-Intensity Intermittent Exercises in Children: an exploratory study Authors : Georges Baquet ${ }^{1}$, Gregory Dupont ${ }^{1,2}$, François-Xavier Gamelin ${ }^{1}$, Julien Aucouturier ${ }^{1}$, Serge Berthoin ${ }^{1}$

\section{Affiliations :}

${ }^{1}$ Univ. Lille, Univ. Artois, Univ. Littoral Côte d'Opale, EA 7369 - URePSSS - Unité de Recherche Pluridisciplinaire Sport Santé Société, F-59000 Lille, France, ${ }^{2}$ The Football Exchange, Research Institute for Sport and Exercise Sciences, Liverpool John Moores University, Liverpool UK

\section{Corresponding author:}

Georges Baquet

EA7369

Faculty of Sport Sciences and Physical Education

Lille University

9, rue de l'Université

F-59790 Ronchin

France

Email : georges.baquet@univ-lille.fr

Running head: Intermittent time to exhaustion 


\begin{abstract}
The study aimed to compare the effect of active versus passive recovery on time to exhaustion (TTE) and time spent at high percentages of peak oxygen uptake during short high-intensity intermittent exercises (S-HIIE) in children. Twelve children ( $9.5 \pm 0.7$ years) underwent a graded test and two S-HIIE (15 s at $120 \%$ of maximal aerobic speed (MAS)), interspersed with either 15-s of active recovery (AR, 50\% of MAS) or 15-s passive recovery $(P R)$ until exhaustion. A very large effect ( $E S=2.42,95 \% \mathrm{Cl}$ [1.32 to 3.52]) was observed for TTE in favour of longer TTE with PR compared to AR. Trivial or small effect sizes were found for peakV $\mathrm{V}_{2}$, peakHR and peakVE between $P R$ and $A R$, while a moderate effect in favour of higher average $\dot{V}_{2}$ values ( $E S=-0.87,95 \% \mathrm{Cl}[-1.76$ to -0.01$]$ ) was found using AR. The difference between PR and AR for the time spent above $80 \%$ (t $80 \%$ ) and $90 \%$ (t90\%) of peakV $\mathrm{O}_{2}$ was trivial. Despite the shorter running duration in $A R$, similar $t 80 \%$ and $t 90 \%$ were spent with $A R$ and $\mathrm{PR}$. Time spent at a high percentage of peakV $\mathrm{V}_{2}$ may be attained by running 3-fold shorter using AR compared using PR.
\end{abstract}

Key Words: Interval training, Aerobic fitness, Maximal oxygen uptake, Field tests 


\section{Introduction}

Intermittent exercises are frequently used by athletes to improve aerobic fitness. They are defined by their exercise intensity and duration, recovery intensity and duration, number of repetitions and number of series. Intermittent exercise is also an intrinsic characteristic of children's spontaneous physical activity. In almost all daily physical activities, free games in the playground, or sports, intermittent activity is more likely to characterize their behavior than continuous activity (37). Bailey et al. (1) and Baquet et al. (4) demonstrated that children's activity is highly transitory, including repeated bursts of activity with rapid recovery.

Short high-intensity intermittent exercise (S-HIIE) allows a high percentage of maximal oxygen uptake $\left(\dot{\mathrm{V}}_{2} \mathrm{max}\right)$ to be elicited in both adults (30) and children (2) and, therefore may be an efficient tool to improve children's aerobic fitness when used during training programs (3). Several studies have suggested a possible link between time spent at high percentage of $\dot{\mathrm{V}} \mathrm{O}_{2} \max \left(\mathrm{t} \dot{\mathrm{V}} \mathrm{O}_{2} \mathrm{max}\right.$, i.e between $80 \%$ and $100 \%$ of $\left.\dot{\mathrm{V}} \mathrm{O}_{2} \mathrm{max}\right)$ during training and training efficiency $(12,24)$. In adults, this parameter has been measured during continuous or intermittent exercises performed until exhaustion (40).

For S-HIIE, active recovery (AR) is generally recommended rather than passive recovery (PR) to reduce blood lactate concentration (8). Active recovery at around $30 \%-60 \%$ of individual $\dot{\mathrm{V}}_{2} \max (26)$ aimed increasing blood lactate removal allowing a potential improvement of recovery (17) and/or maintaining $\mathrm{VO}_{2}$ at a sufficient level to allow physiological adaptations. However, when performing S-HIIE (15 s) at $120 \%$ of maximal aerobic speed (MAS) intercepted with either AR (50\% MAS) or PR, Dupont and Berthoin (15) and Dupont et al. (14) have measured longer time to exhaustion (TTE) with PR compared with AR and similar $\mathrm{VVO}_{2}$ max whatever the recovery mode in adults. With adolescents, when performing S-HIIE (30 s) at $105 \%$ of MAS intercepted with either AR (50 $\% \mathrm{MAS}$ ) or PR, AR yielded a shorter TTE with a proportionally longer $\mathrm{VV}_{\mathrm{V}} \mathrm{O}_{2} \mathrm{max}$, while $\mathrm{PR}$ allowed a longer TTE for similar $\mathrm{tVO}_{2} \max (32)$. A significant reduction in the slope describing the increase in $\dot{\mathrm{V}} \mathrm{O}_{2}$ with lower recovery intensity (9) and faster $\dot{\mathrm{V}} \mathrm{O}_{2}$ kinetics and a higher $\dot{\mathrm{V}} \mathrm{O}_{2}$ peak with AR (10) may explain these differences in TTE between S-HIIE with AR and PR. During AR, the higher level of $\dot{\mathrm{VO}}_{2}$ throughout the end of exercise, which may significantly limit the replenishment of the alactacid and oxyhemoglobin energy sources, which are partially depleted during the previous run interval, and the lower acidosis level could account for the shorter TTE $(9,14)$.

What's about children? To our knowledge, no study has examined the effect of recovery mode in this population. Compared to adults, children show specific physiological responses to exercise, such as faster rest-to-exercise $\dot{\mathrm{V}} \mathrm{O}_{2}$ transitions (19), faster recovery $(27,38)$, lower anaerobic capacity $(38)$, higher ability to repeat supramaximal exercises (28) and differences in ratings of perceived exertion as a function of exercise duration (34). All these factors may have a potential significant influence on intermittent performances (18) and on time spent at high percentages of $\dot{\mathrm{V}}_{2 \max }$ during such exercises.

The primary endpoint for determining which recovery modality was the most relevant in terms of performance was TTE. Since there were no studies in children, we relied on a study in adults by Dupont et al. (14). Thus, the effects of recovery mode on TTE and $\mathrm{t} \dot{\mathrm{V}} \mathrm{O}_{2}$ max reported for adolescents and adults should not be inferred to the children. It could be expected that they demonstrate longer TTE than adolescents and adults with PR or AR and maybe longer $\mathrm{tV}_{2}$ max than adults. Moreover, as demonstrated in adolescents and adults, S-HIIE with PR would allow children to show longer TTE than with AR and to remain at a high percentage of $\mathrm{VO}_{2}$ as long as with AR. Baquet et al. (5) have shown that S-HIIE protocols of exercise bouts of either 10 -s or 20 -s at an intensity above MAS, of total equal duration and using PR generate similar exercise time above $95 \%$ of peak oxygen uptake (VO $\mathrm{V}_{2}$ peak). It would be interesting to compare such exercises using AR and PR. Under what conditions can these S-HIIE exercise modalities be used interchangeably to get the same cardiorespiratory solicitation in children and so to vary the workouts? The manipulation of exercise characteristics (intensity, duration), and of work and recovery periods during S-HIIE protocols determines the amount of time spent at exercise intensity close to $\mathrm{VO}_{2}$ peak. It is therefore important to determine which recovery modality elicits the largest amount of time at a high percentage of $\mathrm{VO}_{2 \max }$ over exercise duration typically shorter than $30 \mathrm{~min}$. In addition, $120 \%$ of MAS in a SHIIE seems an interesting intensity for the time spent at high percentages of $\mathrm{VO}_{2}$ peak compared to a continuous exercise at $80-85 \%$ MAS of the same duration (5).

Therefore, this study was designed to compare the effects of active vs. passive recovery on TTE, and time spent at high percentages of $\dot{\mathrm{V}}_{2}$, during short-term intermittent runs (15s) interspersed with short recovery periods (15s) in children. An additional goal of this study was also to show how these two exercises were perceived. The knowledge of these results could be of particular importance to calibrate exercises duration when S-HIIE are used for training purpose. From Dupont's et al. data (14), a sample of 12 children was chosen and a statistical 
power of $80 \%$ was expected. Also, the present study was considered as exploratory.

\section{Methods}

\section{Participants}

Eleven 8-to-11-year-old children ( 5 boys and 6 girls) volunteered to participate in this study, which had received approval from the Local Committee for Person's Protection in Biomedical Research. The children and their parents signed written informed consent in accordance with the ethical standards of the Helsinki Declaration of 2013. They were informed of the assessment of sexual maturity using breast, pubic hair and genital development by a physician. Height and body mass were measured with a wall stadiometer (Vivioz Medical) and a calibrated beam balance (Tanita TBF 543), respectively. Percentage body fat was estimated from skinfold thickness measured at three sites (biceps, triceps and calf), in line with Lohman recommendations (21). Sexual maturity was evaluated based on pubertal stages: indices of breast, pubic hair and genital development (31). The same physician undertook all observations visually. At the beginning of the study, all participants were at stage 1 of sexual maturity. The anthropometric data were combined, as no difference was found between boys and girls. The mean values for age, body mass, height, and estimated percentage body fat were: $9.6 \pm 0.8$ years, $1.38 \pm 0.07$ $\mathrm{m}, 37.7 \pm 11.2 \mathrm{~kg}$ and $22.8 \pm 4.5 \%$, respectively.

\section{Overview}

The children performed three field tests over a three-week period, one maximal graded field test and two SHIIEs. The tests were performed at the same time of the day $( \pm 1 \mathrm{~h})$. Before entering the study, the children were familiarized with the testing modalities and the gas analyzer device. All tests were performed outdoors on a covered and non-slick surface with an ambient temperature ranging from 16 to $22^{\circ} \mathrm{C}$. During the first session, peak oxygen uptake (peakViO ${ }_{2}$ ) and MAS (6) were assessed. The $2 \mathrm{~S}-\mathrm{HIIE}$, with PR or AR, were performed in a random order. During all the tests, the children were verbally encouraged to run until exhaustion. To avoid any problem linked to a child's inability to maintain a constant speed, they always ran with a trained adult. In all cases, the tests ended when the children could no longer maintain the required running velocity, despite vigorous encouragements. The outcome measures were peakVंO ${ }_{2}$, peak $\mathrm{HR}, \mathrm{TTE}$, and time spent at a high percentage of

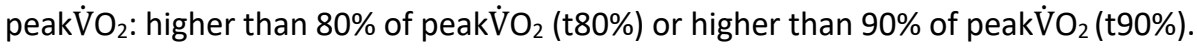

During all tests, Children's OMNI perceived exertion scale (RPE, 36) and the feeling scale (FS, 29) were used to assess subjective measurement of the physiological stress induced by both S-HIIE and ongoing affective responses. The two scales were displayed in a random order within the first minute by the end of each test.

\section{Procedure}

Maximal graded field test. The test started with an initial velocity of $6 \mathrm{~km} \cdot \mathrm{h}^{-1}$, and then the speed was increased by $1.5 \mathrm{~km} \cdot \mathrm{h}^{-1}$ per $3-\mathrm{min}$ stage. The speed in the last completed stage was considered as the MAS (6). MAS was increased by $0.5 \mathrm{~km} . \mathrm{h}^{-1}$, if the child was able to run for 1 min during the last stage; or $1 \mathrm{~km} \cdot \mathrm{h}^{-1}$, if he or she was able to run for $2 \mathrm{~min}$. During the test, the velocities were controlled using a computer. This test was performed on a 150-m track marked with cones every $25 \mathrm{~m}$. The computer emitted a brief sound that indicated to the children the moment when they had to pass by a cone to maintain a constant speed. During the graded test, respiratory gas exchange values were measured breath by breath using a portable system (Cosmed K4b², Rome, Italy) to determine ventilation $\left(\dot{\mathrm{V}}_{\mathrm{E}}\right)$, oxygen uptake $\left(\dot{\mathrm{VO}}_{2}\right)$, and carbon dioxide production $\left(\dot{\mathrm{V}} \mathrm{CO}_{2}\right)(22)$. Before each test, the $\mathrm{O}_{2}$ and $\mathrm{CO}_{2}$ analysis systems were calibrated using ambient air and gases of known $\mathrm{O}_{2}(16 \%)$ and $\mathrm{CO}_{2}$ (5\%) concentrations. For the calibration of the turbine flowmeter of the $\mathrm{K}_{4} \mathrm{~b}^{2}$, a 3-I syringe (Quinton Instruments, Seattle, Wash., USA) was used. Heart rate (HR) was continuously monitored (Polar Accurex+, Polar Electro, Kempele, Finland). The compact device was easy to attach without constricting the children's movements. For subsequent analysis, $\mathrm{VO}_{2}$ and $\mathrm{HR}$ values were averaged at 15 -s periods.

The peakلن ${ }_{2}$ was determined as the highest $15 \mathrm{~s} \dot{V}_{2}$ value measured during the graded test. PeakViO ${ }_{2}$ was accepted as a maximal index, when the maximal HR (HRmax) reached a value above $195 \mathrm{bpm}$ or when the respiratory exchange ratio (RER) was higher than 1 , associated with visible exhaustion (35). 
MAS, interspersed with 15-s of either PR or AR. The AR period was set at $50 \%$ of MAS. These two tests were performed in a random order and were preceded by a standardized warm-up involving a 3-min run at $7.5 \mathrm{~km} \cdot \mathrm{h}-$ ${ }^{1}$. To complete the two S-HIIEs, running paces were given by a manual timer, producing a sound every 15 -s from the start to the end of the exercise. During the 15-s exercise period, the child had to cover a distance based on their own MAS (Figure 1). For the PR procedure, a 15-s PR period was allowed between each 15-s run. After the 15-s rest, the children started to run again in the opposite direction for 15-s. In contrast, in line with Dotan et al. (11), the AR procedure consisted of a 15-s shuttle run at 50\% of MAS (see Figure 1 for more details)

\section{Recovery \\ 15 -s run at $50 \%$ of MAS}

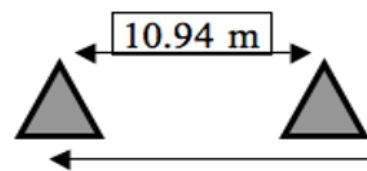

$52.5 \mathrm{~m}$

\section{Exercise}

\section{Recovery}

15 -s run at $50 \%$ of MAS

\section{5 -s run at $120 \%$ of MAS}

Figure 1. An example of the pattern for intermittent runs for a child with a MAS of $10.5 \mathrm{~km} \cdot \mathrm{h}^{-1}$

For PR, the child had to run between the two outer cones separated by $52.50 \mathrm{~m}(120 \%$ of MAS) and stop at the outer cone. For AR, the child returned to the opposite end and slowed down to run $21.88 \mathrm{~m}$ within $15 \mathrm{~s}$ in the form of a shuttle run between the outer and the inner cone.

During the tests, respiratory gas exchange values were measured as for the graded field test. TTE and distance to exhaustion (DTE) were measured for AR and PR. Recovery periods were included in the TTE which was measured to the nearest second. For the AR session, the run at $50 \%$ of MAS was included in DTE. $\dot{V} \mathrm{O}_{2}$ was averaged per 15 s periods and the highest values of $\mathrm{HR}$ and $\dot{\mathrm{VO}}_{2}$ were retained as peakHRPR and peak $\dot{\mathrm{V}} \mathrm{O}_{2 \mathrm{PR}}$ for $P R$, and peakHR $A R$ and peakVंO ${ }_{2 A R}$ for $A R$.

The time spent above $80 \%$ peakن்O ${ }_{2}$ (t80\%), or higher than $90 \%$ peakن் ${ }_{2}$ (t90\%) were calculated for both S-HIIEs and corresponded to the amount of time spent (number of $15 \mathrm{~s}$ bouts) above 80 and $90 \%$ of the peakVंO $\mathrm{N}_{2}(15)$. The time to reach peakن் ${ }_{2}$ was also assessed.

\section{Statistical analysis}

The normality distribution of the data was checked with the Kolmogorov-Smirnov test. Then, a Wilcoxon matched-pairs signed rank test was used to compare TTE, DTE, number of runs, average $\dot{\mathrm{VO}}_{2}$, peakV $\dot{\mathrm{V}}_{2}$, average $\mathrm{HR}$, peakHR, PeakVE, $\mathrm{t} 80 \%$, t90\%, time to reach peakV $\mathrm{V}_{2}$, time spent above $80 \%$ and $90 \%$ of peakHR, RPE and FS values between PR and AR. Data are expressed as mean \pm SD. Regression analysis was used to assess the relationship between TTE of the PR and AR. In all analyses, the level of significance was set at $p<0.05$. Data were analyzed with Prism 7.1d (Graphpad Software Inc, La Jolla). The threshold for statistical significance was set at $\mathrm{p}<0.1$, as the present study was considered as exploratory.

The statistical analysis reached a power from 38 to $80 \%$ for the measured parameters.

Cohen's $d$ corrected by Hopkins was calculated to determine the effect size (ES) that was assessed using the following criteria: $0 \leq \mathrm{ES} \leq 0.2=$ trivial, $0.2<\mathrm{ES} \leq 0.6=$ small, $0.6<\mathrm{ES} \leq 1.2=$ moderate, $1.2<\mathrm{ES} \leq 2.0=$ large, 2.0 $<\mathrm{ES} \leq 4.0$ = very large, $>4.0=$ nearly perfect (20). To calculate the ES, the mean difference was defined as the PR value less the AR value for all the outcomes. The confidence interval $(\mathrm{Cl})$ was set at $95 \%$.

\section{Results}

The cardiorespiratory data were combined, as no difference was found between gender. The maximal values measured during the graded field test for $\dot{\mathrm{VO}}_{2}, \dot{\mathrm{V}} \mathrm{E}, \mathrm{HR}, \mathrm{RER}$, and MAS were: $44.5 \pm 6.2 \mathrm{ml} \cdot \mathrm{kg}^{-1} \cdot \mathrm{min}^{-1}, 1932 \pm 451$ 
$\mathrm{ml} \cdot \mathrm{kg}^{-1} \cdot \mathrm{min}^{-1}, 199 \pm 5 \mathrm{bpm}, 1.15 \pm 0.1,10.4 \pm 1.0 \mathrm{~km} \cdot \mathrm{h}^{-1}$, respectively.

The mean and peak cardiorespiratory values ( $\dot{\mathrm{V} E}, \dot{\mathrm{V}} \mathrm{O}_{2}$, and $\mathrm{HR}$ ), TTE, DTE, $\mathrm{t} 80 \%$, $\mathrm{t} 90 \%$, time to reach peak $\dot{\mathrm{VO}}_{2}$ and times spent above $80 \%$ and $90 \%$ of peakHR, for AR and PR, are displayed in Table 1.

A very large effect for TTE $(p<0.001)$ and a large one for DTE $(p<0.001)$ were found in favour of higher PR values when compared with AR. No significant relationship was found between TTE of AR and TTE of the PR $\left(r^{2}=0.08\right.$, $p>0.05)$.

Trivial or small effect sizes were found for cardiorespiratory responses between PR and AR ( $p>0.05)$, while a moderate effect in favour of higher $A R$ values ( $E S=-0.87,95 \% \mathrm{Cl}[-1.76$ to -0.01$]$ ) was found for the average $\mathrm{V}_{2}$ $(p<0.05)$. Figure 2 shows an example of the $\mathrm{VO}_{2}$ vs time relationship for $A R$ and PR.

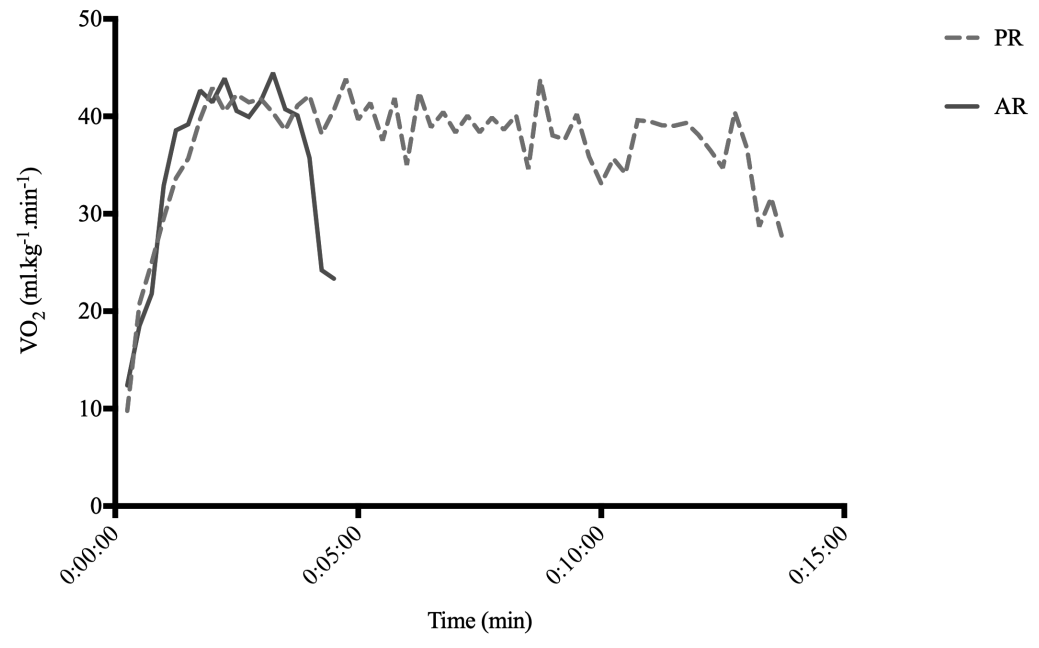

Figure 2: An example of the $\dot{\mathrm{VO}}_{2}$ vs. time relationship during the AR (-) and the PR (--)

The difference between the two intermittent exercises for $t 80 \%$ and $t 90 \%$ was trivial $(p<0.05)$. The time spent above $80 \%$ of peakHR showed a very large effect $(p<0.01)$ and time spent above $90 \%$ of peakHR a large effect in favour of higher PR values when compared with AR $(p<0.1)$.

Eight and six children elicited peakن் ${ }_{2}$, during S-HIIE, with $\mathrm{AR}$ and PR respectively. The time to reach peakV $\mathrm{O}_{2}$ showed a large effect $(p<0.01)$ in favor of a higher value for PR $(322 \pm 202 s)$ when compared to AR $(112 \pm 45 s)$.

RPE values showed a small effect and FS values a trivial one ( $p>0.05)$.

Table 1. Comparison of mean \pm SD values for time to exhaustion, cardiorespiratory measurements, time spent above $80 \%$ and $90 \%$ of peakV $\mathrm{V}_{2}$, peakHR, time to reach peakV் between S-HIIE

\begin{tabular}{|c|c|c|c|c|}
\hline Number of participants: 11 & $\begin{array}{l}\text { S-HIIE } \\
\text { with PR }\end{array}$ & $\begin{array}{l}\text { S-HIIE } \\
\text { with AR }\end{array}$ & $\begin{array}{l}\text { Mean of differences } \\
\qquad[95 \% \mathrm{Cl}]\end{array}$ & Effect size $[95 \% \mathrm{Cl}]$ \\
\hline TTE $(s)$ & $622 \pm 215 * * * *$ & $201 \pm 92$ & $421[273.9$ to 568.1$]$ & 2.42 [1.32 to 3.52$]$ \\
\hline $\mathrm{DTE}(\mathrm{m})$ & $1070 \pm 418^{* * * *}$ & $428 \pm 226$ & 642 [343.1 to 940.9$]$ & $1.81[0.82$ to 2.81$]$ \\
\hline Number of runs (n) & $41.5 \pm 14.3 * * * *$ & $13.3 \pm 6.1$ & 28.82 [17.46 to 40.17$]$ & 2.31 [1.28 to 2.35$]$ \\
\hline Average $\dot{\mathrm{V}} \mathrm{O}_{2}\left(\mathrm{ml} \cdot \mathrm{kg}^{-1} \cdot \mathrm{min}^{-1}\right)$ & $31.1 \pm 5.2$ & $35.8 \pm 4.9 * *$ & $-4.61[-9.28$ to -0.12$]$ & $-0.87[-1.76$ to -0.01$]$ \\
\hline
\end{tabular}




\begin{tabular}{|c|c|c|c|c|}
\hline $\mathrm{PeakV்}_{2}\left(\mathrm{ml} \cdot \mathrm{kg}^{-1} \cdot \mathrm{min}^{-1}\right)$ & $41.3 \pm 6.1$ & $44.3 \pm 4.4$ & $-3.0[-7.73$ to 1.73$]$ & $-0.54[-1.39$ to 0.32$]$ \\
\hline Average HR (bpm) & $180 \pm 4$ & $177 \pm 10$ & $3[-3.77$ to 9.77$]$ & $0.37[-0.47$ to 1.22$]$ \\
\hline Peak HR (bpm) & $191 \pm 4$ & $191 \pm 4$ & $0[-3.56$ to 3.56$]$ & $0[-0.84$ to 0.84$]$ \\
\hline Peak $\dot{V} E\left(\mathrm{ml} \cdot \mathrm{kg}^{-1} \cdot \mathrm{min}^{-1}\right)$ & $1703 \pm 343$ & $1712 \pm 244$ & $-9[-273$ to 255$]$ & $-0.03[-0.86$ to 0.81$]$ \\
\hline $\begin{array}{l}\text { Time spent above } 80 \% \text { of } \\
\text { peakن을 }\end{array}$ & $151 \pm 173$ & $113 \pm 111$ & $38[-91.28$ to 167.28$]$ & $0.25[-0.59$ to 1.09$]$ \\
\hline $\begin{array}{l}\text { Time spent above } 90 \% \text { of } \\
\text { peakن் } \\
\text { peas }\end{array}$ & $41 \pm 56$ & $72 \pm 116$ & $-31[-112.01$ to 50.01$]$ & $-0.32[-1.16$ to 0.52$]$ \\
\hline Time to reach peakلi $\mathrm{O}_{2}(\mathrm{~s})$ & $322 \pm 202^{* * *}$ & $112 \pm 45$ & 210.0 [79.84 to 340.16$]$ & 1.36 [0.43 to 2.29$]$ \\
\hline $\begin{array}{c}\text { Time spent above } 80 \% \text { of } \\
\text { peakHR (s) }\end{array}$ & $568 \pm 230 * *$ & $173 \pm 106$ & 395 [235.72 to 554.28$]$ & 2.09 [1.05 to 3.13$]$ \\
\hline $\begin{array}{c}\text { Time spent above } 90 \% \text { of } \\
\text { peakHR (s) }\end{array}$ & $318 \pm 230 *$ & $126 \pm 105$ & 192 [32.98 to 351.02$]$ & 1.02 [0.13 to 1.91$]$ \\
\hline $\begin{array}{l}\text { Ratings of Perceived } \\
\text { Exertion }\end{array}$ & $8.0 \pm 2.5$ & $7.3 \pm 2.4$ & $0.7[-1.17$ to 3.37$]$ & $0.41[-1.48$ to 2.88$]$ \\
\hline Feeling Scale & $-0.7 \pm 4.1$ & $-0.2 \pm 4.2$ & $-0.50[-4.19$ to 3.19$]$ & $-0.11[-0.95$ to 0.72$]$ \\
\hline
\end{tabular}

$\mathrm{Cl}$ : confidence interval; TTE: time to exhaustion; DTE: distance to exhaustion; $\dot{\mathrm{VO}}_{2}$ : oxygen uptake; PeakVंO ${ }_{2}$ : peak oxygen uptake; HR: heart rate; PeakHR: peak heart rate; PeakVE: peak ventilation.

$* * * *$ : significantly different at $p<0.001 ; * * *$ : significantly different at $p<0.01 ;{ }^{* *}$ : significantly different at $p<0.05 ; *$ : significantly different at $p<0.1$

\section{Discussion}

The aim of this study was to investigate the effects of the type of recovery (active vs. passive) on TTE and tpeak $\mathrm{VO}_{2}$ during high-intensity intermittent runs (15s) at $120 \%$ of MAS in prepubertal children. The main results of the study were that, for this type of exercise, peakV $\mathrm{V}_{2}$ achieved and $\mathrm{t} 80 \%$ or $\mathrm{t} 90 \%$ were not different between $P R$ and $A R$, while time to reach peakV ${ }_{2}$ was faster in $A R$ compared to $P R$, and TTE and DTE were greater with PR than with $A R$.

\section{Times to Exhaustion}

The TTE for PR was significantly longer than for AR. The children ran three times as long and covered double distance with PR as with AR. In a previous study, during S-HIIE with PR at $120 \%$ of MAS, Berthoin et al. (7) have found a comparable TTE (421 $\pm 121 \mathrm{~s})$ with prepubertal children. Moreover, TTE, reported in the present study, were similar to those found by Berthoin et al. (7) during continuous running at $90 \%(667 \pm 311 \mathrm{~s})$ and $100 \%$ of MAS (244 $\pm 79 \mathrm{~s})$. Children seemed to respond to the same manner whether using continuous or intermittent exercises. With a 30-s interval runs at $110 \%$ of MAS, interspersed with 30 s of either PR or AR, Thévenet et al. (32) showed double TTE values with PR than with AR ( $2145 \pm 829 \mathrm{~s}$ vs $1072 \pm 388 \mathrm{~s})$. These results suggest that for S-HIIE (equal or shorter than 30s) with equal exercise/recovery ratio, AR lead to shorter TTE in children compared to PR, that is similar to previously results reported for adolescents. In adults, Dupont (16) showed also a shorter TTE in similar S-HIIE followed by AR. They suggested that this shorter TTE might partly be explained by a higher energy requirement during the $A R$ procedure.

In the present study, AR resulted in moderately greater average $\mathrm{VO}_{2}$ than $\mathrm{PR}(\mathrm{ES}=-0.87,95 \% \mathrm{Cl}[-1.76$ to -0.01$]$, $\mathrm{p}<0.05)$. For comparable exercises, Dupont et al. (16) showed that deoxygenation during AR was higher than during PR and suggested that $\mathrm{VO}_{2}$ necessary for AR impaired myoglobin and hemoglobin oxygen replenishments, 
as well as the resynthesis of phosphocreatine stores. $\mathrm{VO}_{2}$ kinetics, myoglobin and hemoglobin oxygenation and phosphorylcreatine resynthesis certainly contribute to the performance during S-HIIE. However, no significant relationship was found between TTE between AR and PR, indicating that children who maintained the longest TTE with AR were not those who maintained the longest time with PR. During the exercise phase, children who reached a high percentage of $\mathrm{VO}_{2}$ max faster might have a lower $\mathrm{O}_{2}$ deficit and hence could maintain the exercise longer. During the recovery period, children who experience faster phosphocreatine resynthesis and in whom replenishments in oxygen are greater should show less fatigue $(16,27)$.

Even if children are characterized by a faster adjustment of oxygen uptake to oxygen requirement at the onset of exercise (19) and a faster recovery after S-HIIE $(27,38)$, which could partly be explained by the children's ability to regulate the changes in acid-base balance more efficiently (28), Zafeiridis et al. (40) have shown, with 30s-runs at $110 \%$ of MAS with $30 \mathrm{~s}$ of recovery at $50 \%$ of MAS, that they are not able to perform for as long as adults. At $120 \%$ of MAS, there is certainly a high anaerobic contribution in terms of the energy requirement and children have a lower anaerobic capacity (38).

\section{Time Spent at a high percentage of peakV $\mathrm{O}_{2}$}

In adults, several authors $(12,13,25)$ demonstrated that it was possible to reach and spend time at $\mathrm{VO}_{2}$ max with S-HIIE. The time maintained at a high percentage of $\dot{\mathrm{V}}_{2} \max$ can be a key factor in improving $\dot{\mathrm{VO}}_{2}$ max during training. Using a similar S-HIIE, Baquet et al. (2) showed that children elicited a high percentage of peak $\mathrm{VO}_{2}$ and even reached peak $\mathrm{VO}_{2}$. This may explain training programs with such exercises are efficient to increase peak $\mathrm{VO}_{2}$ and/or aerobic performance in children (3). In previous studies investigating the peak $\mathrm{VO}_{2}$ response using S-HIIE $(2,5)$, short bursts of exercises were interspersed with PR periods only. The nature and the intensity of the recovery might be another key factor in the increase in $\mathrm{V}_{2}$ max or performance (33). If the recovery intensity is too high, TTE and then $\mathrm{tV}_{2}$ max may be reduced (23). Thévenet et al. (33) have suggested that AR at $50 \%$ of MAS seems to be the best compromise to induce substantial solicitations of the aerobic system.

Over a single exercise session, physiological stress is often quantified by the amount of time spent above various thresholds of $\mathrm{V}_{2}{ }_{2 m a x}$, ranging from $80 \%$ to $95 \%$ (39). Anyway, to elicit significant improvement in peakV $\mathrm{O}_{2}$ in children and adolescents, the exercise intensity higher than $80 \%$ of the peak heart rate (3) has been suggested. In the present study, all the children have reached $80 \%$ of peak $\mathrm{VO}_{2}$ whatever the recovery mode. With $\mathrm{AR}, 11$ children have reached $90 \%$ of peakV $\mathrm{V}_{2}$ and 8 children reached peakViO ${ }_{2}$. With $\mathrm{PR}, 7$ children have reached $90 \%$ of peak $\mathrm{V}_{2}$ and 6 children reached peakV $\mathrm{O}_{2}$. For both S-HIIE, the interaction between intensity and duration of exercise and recovery periods was adequate to allow participants to reach and to maintain a high percentage of peakنंO $\mathrm{V}_{2}$.

During S-HIIE, our findings suggest that AR and PR allow similar amounts of time spent at a high percentage of peakViO ${ }_{2}$, although time to reach peakV $\mathrm{V}_{2}$ was significantly shorter with $\mathrm{AR}(318 \pm 230$ vs $126 \pm 105 \mathrm{~s}$ for $\mathrm{PR}$ and $A R$, respectively). Recovery mode had no influence on $t 90 \%$ and $t 80 \%$. This result can be explained by the smallness of our sample. From data of Dupont's et al. (14), a sample of 12 children was chosen and a statistical power of $80 \%$ was expected. This sample was sufficient to see a difference in TTE, but not to highlight a significant difference between the two recovery modalities for time spent at a high level of $\mathrm{VO}_{2}$ peak. For this parameter, we only reached a power of $38 \%$, which confirmed the exploratory nature of this study. With similar exercises, Dupont \& Berthoin (15) reported longer t90\% in adults compared to children, whatever the recovery mode (282 $\pm 117 \mathrm{~s}$ and $317 \pm 132 \mathrm{~s}$, for $A R$ and PR respectively). However, they did not show a significant difference in t90\% between the two types of recovery. The present results are also in line with those by Thévenet et al.'s (32) study which also showed no difference in t90\% (746 $\pm 417 \mathrm{~s}$ and $548 \pm 499 \mathrm{~s}$, for AR and PR respectively) using a short intermittent exercise (30s at $105 \%$ of MAS with 30 s of recovery).

To spend equal time at high percentages of peak $\mathrm{VO}_{2}$ with active recovery mode, a greater number of shuttles is required with PR. Thus, S-HIIE with AR seems to be more efficient than PR when the sole objective of training is to sustain at a high percentage of peakV ${ }_{2}$ as children run less time for the same value of tpeakV $\mathrm{O}_{2}$. In contrast, S-HIIE with PR allows a longer TTE at a high intensity (120\% of MAS) and longer time spent at $80 \%$ and $90 \%$ of peakHR, that should increase endurance performance by further soliciting the neuromuscular system (32) and the cardiorespiratory system. With short intermittent runs of $15 \mathrm{~s}$ at velocities ranging from 110 to $140 \%$ of MAS, Dupont et al. (12) demonstrated that the longest $t \mathrm{~V}_{2}$ max in adults was obtained at $120 \%$ of the MAS. Further studies are needed to investigate the best interaction between, intensity, duration and recovery in S-HIIE to allow 
children to reach and maintain the highest time at a high percentage of peak $\mathrm{VO}_{2}$.

\section{Rating of Perceived Exertion and affective response}

Despite TTE difference between AR and PR and the higher average cardiorespiratory response in AR, no difference was observed between recovery modalities for RPE and SE. Children perceived the two exercises to be very difficult but seemed to have no negative feeling for this kind of exercise, whatever modality. Trainers can therefore use both S-HIIE interchangeably in a perspective to maintain the motivation of children during training.

\section{Practical applications}

$A R$ is a particular form of continuous activity with variation of velocity while PR is a sequence of repeated exercise periods interspersed with intervals of incomplete rest (14). In S-HIIE with short recovery periods the recovery mode has a significant influence on performances (i.e: TTE) and cardiorespiratory responses (i.e: average $\mathrm{V}_{2}$ ). For training applications, these exercises are different. During training, it could be recommended that the number of repetitions with PR should be greater than with AR to spend a similar time at high percentages of peak $\mathrm{VO}_{2}$. As improvements in peak $\mathrm{VO}_{2}$ are explained by the high level of $\dot{\mathrm{VO}}_{2}$ afforded by the exercises, trainers can use the two modalities to improve aerobic fitness. However, the choice of the recovery depends on training aim. Active recovery can be chosen when trainers want to improve peakV $\mathrm{O}_{2}$.

\section{Conclusion}

In summary, children performing high intensity (120\% of MAS) short duration (15s) exercises interspersed with AR exhibited a significant decrease in their running time and distance, compared with the PR protocol. Despite the shorter running duration in $\mathrm{AR}$, an equal time was spent at high percentage of peakV $\mathrm{O}_{2}$ with $\mathrm{AR}$ and $\mathrm{PR}$. Time spent at a high percentage of peakV $\mathrm{V}_{2}$ may be attained by running 3 -fold shorter using AR compared using PR. 


\section{References}

1. Bailey RC, Olson J, Pepper SL, Porszasz J, Barstow TJ, Cooper DM. The level and tempo of children's physical activities: an observation study. Med Sci Sport Exerc. 1995;27:1033-1050.

2. Baquet G, Berthoin S, Dupont G, Blondel N, Fabre C, Van Praagh E. Effects of high intensity intermittent training on peakV $\mathrm{V}_{2}$ in prepubertal children. Int J Sports Med. 2002;23:439-444.

3. Baquet G, Van Praagh E, Berthoin S. Endurance training and aerobic fitness in young people. Sports Med. 2003;15:1127-1145.

4. Baquet G, Stratton G, Van Praagh E, Berthoin S. Improving physical activity assessment in prepubertal children with high-frequency accelerometry monitoring: a methodological issue. Prev Med. 2007;44(2):143-147.

5. Baquet G, Gamelin FX, Aucouturier J, Berthoin S. Cardiorespiratory Responses to Continuous and Intermittent Exercises in Children. Int J Sports Med. 2017;38(10):755-762. doi: 10.1055/s-0043-111892

6. Berthoin S, Baquet G, Rabita J, Blondel N, Lensel-Corbeil G, Gerbeaux M. Validity of the Université de Montréal track test to assess maximal aerobic speed for adolescents. J Sports Med Phys Fitness. 1999;39:107-112.

7. Berthoin S, Baquet G, Dupont G, Blondel N, Mucci P. Critical velocity and anaerobic distance capacity in prepubertal children. Can J Appl Physiol. 2003;28:561-575.

8. Billat LV. Interval training for performance: a scientific and empirical practice. Special recommendations for middle- and long-distance running. Part I: aerobic interval training. Sports Med. 2001;31(1):13-31.

9. Chidnok W, Dimenna FJ, Bailey SJ, Vanhatalo A, Morton RH, Wilkerson DP, Jones AM. Exercise tolerance in intermittent cycling: application of the critical power concept. Med Sci Sport Exerc. 2012;44(5):966976.

10. Dorado C, Sanchis-Moysi J, Calbet JA. Effects of recovery mode on performance, $\mathrm{O}_{2}$ uptake, and $\mathrm{O}_{2}$ deficit during high-intensity intermittent exercise. Can J Appl Physiol. 2004; 29(3):227-244.

11. Dotan R, Falk B, Raz A. Intensity effect of active recovery from glycolytic exercise on decreasing blood lactate concentration in prepubertal children. Med Sci Sport Exerc. 2000;32(3):564-570.

12. Dupont G, Blondel N, Lensel-Corbeil G, Berthoin S. Critical velocity and time spent at $\mathrm{VO}_{2} \max$ for short intermittent runs at supramaximal velocities. Can J Appl Physiol. 2002;27:103-115.

13. Dupont G, Berthoin S. Time spent at $\dot{V}_{2}$ max: A methodological issue. Int J Sports Med. 2003;24:291296.

14. Dupont G, Blondel N, Berthoin S. Performance for short intermittent runs: active recovery vs passive recovery. Eur J Appl Physiol. 2003;89:548-554.

15. Dupont $\mathrm{G}$, Berthoin $\mathrm{S}$. Time spent at a high percentage of $\mathrm{VO}_{2}$ max for short intermittent runs: active versus passive recovery. Can J Appl Physiol. 2004;29(Suppl.):S3-S16.

16. Dupont G, Moalla W, Guinhouya C, Ahmaidi S, Berthoin, S. Passive versus active recovery during highintensity intermittent exercise. Med Sci Sport Exerc. 2004;36:302-308.

17. Fairchild TJ, Armstrong AA, Rao A, Liu H, Lawrence $S$, Fournier PA. Glycogen synthesis in muscle fibers during active_recovery_from intense exercise. Med Sci Sports Exerc. 2003;5(4):595-602.

18. Falk B, Dotan R. Child-adult differences in the recovery from high-intensity exercise. Exercise and Sport Science Review. 2006;34:107-112.

19. Fawkner SG, Armstrong N. Oxygen uptake kinetic response to exercise in children. Sports Med. 2003;33:651-669.

20. Hopkins W. A scale of magnitudes for effect statistics. A New View of Statistics; 2002, Retrieved from http: //www.sportsci.org/resource/stats/effectmag.html.

21. Lohman TG. Advances in Body Composition Assessment. Current issues in exercise science series (Monograph N³). Champaign, IL: Human Kinetics; 1992, pp. 65-77.

22. McLaughlin JE, King GA, Howley ET, Bassett DR Jr, Ainsworth BE. Validation of the COSMED K4 $\mathrm{b}^{2}$ portable metabolic system. Int J Sports Med. 2001;22:280-284.

23. Midgley AW, Mc Naughton LR. Time at or near $\mathrm{VO}_{2}$ max during continuous and intermittent running. $A$ review with special reference to considerations for the optimisation of training protocols to elicit the longest time at or near $\mathrm{VO}_{2}$ max. J Sports Med Phys Fitness. 2006;46(1):1-14.

24. Midgley AW, McNaughton LR, Wilkinson M. Is there an optimal training intensity for enhancing the maximal oxygen uptake of distance runners? Empirical research findings, current opinions, physiological rationale and practical recommendations. Sports Med. 2006;36:117-132.

25. Millet GP, Candau R, Fattori $P$, Bignet $F$, Varray $A$. $\dot{V} O_{2}$ responses to different intermittent runs at velocity associated to $\dot{\mathrm{VO}}_{2}$ max. Can J Appl Physiol. 2003;28:410-423. 
26. Nédélec M, McCall A, Carling C, Legall F, Berthoin S, Dupont G. Recovery in soccer: part II-recovery strategies. Sports Med. 2013;43:9-22.

27. Ratel S, Bedu M, Hennegrave A, Doré E, Duché P. Effects of age and recovery duration on peak power output during repeated cycling sprints. Int J Sports Med. 2002a;23:397-402.

28. Ratel S, Duché $P$, Hennegrave A, Van Praagh E, Bedu M. Acid-base balance during repeated cycling sprints in boys and men. J Appl Physiol. 2002b;92:479-485.

29. Rejeski WJ. Perceived exertion: An active or passive process? Journal of Sport and Psychology. 1985;7:371-378.

30. Tabata I, Nishimura K, Kouzaki M, Hirai Y, Ogita F, Miyachi M, Yamamoto K. Effects of moderate-intensity intermittent training and high-intensity intermittent training on anaerobic capacity and $\dot{\mathrm{VO}}_{2} \mathrm{max}$. Med Sci Sport Exerc. 1996;28:1327-1330.

31. Tanner JM. Growth at Adolescence ( $\left.2^{\text {nd }} E d\right)$. Oxford, UK: Blackwell; 1962.

32. Thévenet D, Tardieu-Berger M, Berthoin S, Prioux J. Influence of recovery mode (passive vs. active) on time spent at maximal oxygen uptake during an intermittent session in young and endurance-trained athletes. Eur J Appl Physiol. 2007;99(2):133-142.

33. Thévenet D, Leclair E, Tardieu-Berger M, Berthoin S, Regueme S, Prioux J. Influence of recovery intensity on time spent at maximal oxygen uptake in young, endurance-trained athletes. J Sport Sci. 2008;26(12):1313-1321.

34. Timmons BW, Bar-Or O. RPE during prolonged cycling with and without carbohydrate ingestion in boys and men. Med Sci Sport Exerc. 2003; 35:1901-1907.

35. Tolfrey K, Campbell IG, Batterham. Aerobic trainability of prepubertal boys and girls. Pediatr Exerc Sci. 1998;10:248-263.

36. Utter AC, Robertson RJ, Nieman DC, Kang J. Children's OMNI Scale of Perceived Exertion: walking/running evaluation. Med Sci Sport Exerc. 2002;34:139-144.

37. Welk GJ, Corbin CB, Dale D. Measurement issues in the assessment of physical activity in children. Res $Q$ Exerc Sport. 2000;71:59-73.

38. Zafeiridis A, Dalamitros A, Dipla K, Manou, V, Galanis N, Kellis S. Recovery during high-intensity intermittent anaerobic exercise in boys, teens, and men. Med Sci Sport Exerc. 2005;37:505-512.

39. Zafeiridis A, Sarivasiliou H, Dipla K, Vrabas IS. The effects of heavy continuous versus long and short intermittent aerobic exercise protocols on oxygen consumption, heart rate, and lactate responses in adolescents. Eur J Appl Physiol. 2010;110(1):17-26.

40. Zafeiridis A, Rizos S, Sarivasiliou H, Kazias A, Dipla K, Vrabas IS. The extent of aerobic system activation during continuous and interval exercise protocols in young adolescents and men. Appl Physio Nutr Metab, 2011;36(1),128-136. doi: 10.1139/H10-096 